\title{
Effect of isoprenaline and propranolol on left ventricular function as determined by nuclear angiography
}

\author{
R P SAPRU, * W J HANNAN, A L MUIR, H M BRASH, K HARPER \\ From the Department of Medicine and Department of Medical Physics and Medical Engineering, \\ The Royal Infirmary, Edinburgh
}

SUMMARY We have studied changes in left ventricular function with non-invasive nuclear angiography, at rest, during graded infusions of isoprenaline $(0.75,1.0$, and $2.0 \mu \mathrm{g} / \mathrm{min})$, and 10 minutes after a single intravenous injection of propranolol $(0.25 \mathrm{mg} / \mathrm{kg})$. To test the adequacy of beta-adrenoreceptor antagonism, isoprenaline $(2.0 \mu \mathrm{g} / \mathrm{min})$ was reinfused after propranolol. Eight healthy subjects have been studied.

Ventricular volume-time curves were obtained by electrocardiogram-gated accumulation of count rates in sequential $20 \mathrm{~ms}$ time bins (over 500 cardiac cycles) from a selected region of interest corresponding to the left ventricular blood pool. ${ }^{99 \mathrm{~m}} \mathrm{Tc}-\mathrm{HSA}$ was used as the radiopharmaceutical. In addition to the ejection fraction, the mean ejection rate, peak rate of change of volume in systole and diastole, and the mean ejection and filling times were calculated from these volume-time curves. A linear dose dependance has been shown in the changes in ejection fraction, mean ejection rate, peak rate of change of volume in systole, and mean ejection time. After beta-adrenoreceptor antagonism the resting values of various variables were not significantly different from the control values, except for the mean ejection rate. Reinfusion of isoprenaline after beta-adrenoreceptor antagonism was without effect on any of the variables.

This study shows that nuclear angiography provides a satisfactory non-invasive technique for the evaluation of cardiac function, especially when physiological and pharmacological interventions are examined.

Changes in ventricular volume can be measured at nuclear angiography by imaging a suitably labelled blood pool within the heart using a gamma camera system. The electrocardiogram-gated accumulation of radioactivity in sequential time bins yields an activity-time curve from which complementary variables of ventricular function may be measured. Since count rates within the region being sampled are proportional to volume, it is implied that such activity-time curves represent proportional volume change. A good correlation between the ejection fraction measured by this technique and that measured by contrast cineangiography has been reported earlier from this laboratory ${ }^{1}$ and also by other workers. ${ }^{2-4}$ A distinct advantage of this method is that repeated measurements can be made

*Visiting Commonwealth Fellow.

Present address: Department of Cardiology, Sree Chitra Tirunal Medical Centre, Trivandrum 695011, India.

Received for publication 6 September 1979 over a period of at least four hours while physiological and pharmacological interventions are being tested. Furthermore, it is possible to undertake longitudinal investigation of ventricular function in the same patient without undue discomfort.

In order to define the value of this technique in the clinical assessment of cardiac function and, more importantly, sequential changes in cardiac function, we report on the effect of positive inotropic stimulation with infusions of graded doses of isoprenaline and negative inotropic intervention with propranolol in a group of healthy subjects.

\section{Subjects and methods}

These studies were carried out in eight health $\alpha$ subjects drawn from a routine referral service for the investigation of acute chest pain. All subjects had a history of vague chest pain thought to be nonischaemic in origin. They also had normal findings 
on a detailed clinical examination, resting and exercise electrocardiograms (to a workload of $900 \mathrm{kpm}$ ), and chest $x$-ray films. Informed consent was obtained from all subjects and the study had the approval of our hospital ethical committee.

The patients were studied in the supine position. Possible thyroid uptake was blocked by two doses of potassium iodide given orally during the preceding 24 hours.

Cardiac blood pool imaging was performed in the $30^{\circ}$ left anterior oblique projection with a $10^{\circ}$ caudal tilt using a Nuclear Enterprises Mk 5 HR gamma camera fitted with a high resolution parallelhole collimator. Between 12 and $15 \mathrm{mCi}$ of technetium- $99 \mathrm{~m}$ labelled to human serum albumin was injected into the left antecubital vein through an indwelling cannula and flushed in rapidly with a single $20 \mathrm{ml}$ bolus of normal saline.

After resting measurements for 10 minutes, constant rate infusions of isoprenaline were given and cardiac imaging was continued. Three sequential incremental steps of isoprenaline infusion in the dose of $0 \cdot 75,1$, and $2 \mu \mathrm{g} / \mathrm{min}$ were used. Each dose level was maintained for approximately 10 minutes. After this, beta-adrenoreceptor antagonism was produced with a single bolus of $0.25 \mathrm{mg} / \mathrm{kg}$ body weight of propranolol and the recordings repeated after a 10-minute wait. Lastly, isoprenaline infusion at a dose of $2 \mu \mathrm{g} / \mathrm{min}$ was restarted while the measurements were continued.

During the procedure the electrocardiogram from a display unit, heart rate from a digital counter connected to the electrocardiograph, and blood pressure by sphygmomanometry were monitored continuously. The data from the gamma camera, together with a bipolar electrocardiogram derived from the chest leads, were recorded simultaneously in analogue form on videotape.

The ventricular volume curves were generated during replay of the data from the videotapes. ${ }^{1} \mathrm{~A}$ region of interest corresponding to the left ventricle was selected on the gamma camera. Care was taken to exclude the left atrium and the right ventricle from the selected field of view. For measurement of background a crescentic area was defined either just inside or just outside the lateral and inferior margins of the selected left ventricular region. The counts from these two areas were accumulated in sequential $20 \mathrm{~ms}$ time intervals throughout each cardiac cycle beginning with the peak of the $R$ wave on the accompanying electrocardiogram. Approximately 500 consecutive cardiac cycles were sampled for each measurement. The left ventricular region of interest was checked after each intervention in order to avoid errors caused by changes in the enddiastolic volume.
The count rates, along with the $R R$ interval histogram, were transferred to a PDP 12 computer and ventricular volume curves plotted. The digital filtering technique to filter out the high-frequency noise from the raw data is described elsewhere. ${ }^{5}$ Volume curves showing a standard deviation of the RR interval of greater than $60 \mathrm{~ms}$ were rejected. Corrections were made for background counts and the ejection fraction (EF) was calculated. ${ }^{1}$ The volume curve was differentiated to give the peak rate of change of volume in systole $\left(\mathrm{dV}_{\mathrm{s}} / \mathrm{dt}\right)$ and diastole $\left(\mathrm{dV}_{\mathrm{d}} / \mathrm{dt}\right)$. Mean times of ejection $\left(\mathrm{t}_{\mathrm{s}}\right)$ and filling $\left(\mathfrak{t}_{d}\right)$ were calculated from the ventricular curve according to the general equation:

$$
\overline{\mathrm{t}}=\frac{\Sigma\left(\mathrm{V}_{\mathrm{i}}-\mathrm{V}_{\mathrm{i+1}}\right) \cdot \frac{\left(\mathrm{t}_{\mathrm{i}}+\mathrm{t}_{\mathrm{i}+1}\right)}{2}}{\Sigma\left(\mathrm{V}_{\mathrm{i}}-\mathrm{V}_{\mathrm{i+1}}\right)}
$$

for values of $t_{i}$ throughout each phase of the cardiac cycle where $V_{i}$ is the relative volume at time $t_{i}$.

As a weighted mean these times represent the centre of gravity of the corresponding segments of the differentiated volume curve. In order to study the effect on $\tilde{t}_{\mathrm{s}}$ and $\mathfrak{t}_{\mathrm{d}}$ values as a result of changes in the cycle length alone, without changes in inotropy, measurements were made at rest and at peak heart rates after each of two successive injections of atropine (600 $\mu \mathrm{g}$ each). The volume time curves for this purpose were obtained in a similar manner in another six patients recovering from a myocardial infarction.

The left ventricular ejection time (LVET) was measured from the volume-time curve as the interval between the end-diastolic and endsystolic channels. The mean ejection rate was calculated as EF/LVET. The volume curve was normalised to the end-diastolic volume so that the units for various indices, that is peak rate of volume change during systole $\left(\mathrm{dV}_{\mathrm{s}} / \mathrm{dt}\right)$ and diastole $\left(\mathrm{dV}_{\mathrm{d}} / \mathrm{dt}\right)$ and the mean ejection rate are expressed as end-diastolic volumes per second (ED vol/s). Statistical comparisons were made by the Student's $t$ test for paired data.

\section{Results}

The mean data for all subjects are given in Table 1. The heart rate increased from a resting average of 78 beats per min to 106 beats per min at the maximum dose of isoprenaline used. The systolic blood pressure increased slightly $(+13.0 \%)$ and the diastolic blood pressure decreased somewhat 
$(-8.7 \%)$, resulting in the characteristic widening of the pulse pressure during infusions of isoprenaline (Fig. 1). Fig. 2 shows the ventricular volume curves at rest and after each of the pharmacological interventions in one patient. For all subjects the ejection fraction at rest averaged $0.58 \pm 0.06$ (SD) and increased to $0.70 \pm 0.09$ (SD) at an infusion rate of $0.75 \mu \mathrm{g} / \mathrm{min}$ (Iso 1), $0.72 \pm 0.10$ (SD) at an infusion rate of $1 \mu \mathrm{g} / \mathrm{min}$ (Iso 2), and $0.76 \pm 0.08$ (SD) at an infusion rate of $2.0 \mu \mathrm{g} / \mathrm{min}$ (Iso 3). After beta-adrenoreceptor antagonism the mean ejection fraction of $0.52 \pm 0.07$ (SD) was not significantly different from the resting values. Reinfusion of isoprenaline at $2.0 \mu \mathrm{g} / \mathrm{min}$ was now without effect (Fig. 3).

The changes in mean ejection rate were similar with increases of 45, 57, and 97 per cent during incremental doses of isoprenaline. After propranolol mean ejection rate was significantly lower $(14 \%$, $\mathrm{p}<0.02)$ than in the control period, and remained unchanged when $2 \mu \mathrm{g} / \mathrm{min}$ of isoprenaline was reinfused (Fig. 3).

With increasing doses of isoprenaline infusion $\mathrm{dV}_{\mathrm{s}} / \mathrm{dt}$ increased progressively by 18,28 , and 63 per cent relative to the resting value (Fig. 4). After propranolol the mean value was not significantly different from that at rest and no significant change was seen on reinfusion of isoprenaline at a dose rate of $2.0 \mu \mathrm{g} / \mathrm{min}$. The changes in $\mathrm{dV}_{\mathrm{d}} / \mathrm{dt}$ were somewhat variable and did not achieve statistical significance.

The mean ejection time $\left(\mathfrak{t}_{\mathrm{s}}\right)$ declined progressively

Table 1 Changes in left ventricular function after beta-adrenergic stimulation with isoprenaline and beta-adrenoreceptor antagonism with propranolol

\begin{tabular}{|c|c|c|c|c|c|c|}
\hline $\begin{array}{l}\text { Variable } \\
\text { Dose of drug }\end{array}$ & $\begin{array}{c}\text { Rest } \\
0\end{array}$ & $\begin{array}{l}\text { Iso-1 } \\
(0.75 \mathrm{~kg} / \mathrm{min})\end{array}$ & $\begin{array}{l}I s o-2 \\
(1 \mu g / \min )\end{array}$ & $\begin{array}{l}I s o-3 \\
(2 \mu g / \min )\end{array}$ & $\begin{array}{l}\text { Prop. } \\
(0.25 \mathrm{mg} / \mathrm{kg})\end{array}$ & $\begin{array}{l}\text { Prop }+I s o-3 \\
(2 \mu g / \min )\end{array}$ \\
\hline No. of subjects & 8 & 7 & 7 & 8 & 6 & 6 \\
\hline $\begin{array}{l}\text { BP systolic } \\
\text { (mmHz) }\end{array}$ & $118 \pm 1 \cdot 8^{\star}$ & $\begin{array}{l}124 \pm 2.3 \\
(<0.02)\end{array}$ & $\begin{array}{l}126 \pm 2.3 \\
(<0.001)\end{array}$ & $\begin{array}{l}133 \pm 3.2 \\
(<0.001)\end{array}$ & $\begin{array}{l}118 \pm 2 \cdot 0 \\
(>0 \cdot 2)\end{array}$ & $\begin{array}{l}121 \pm 2 \cdot 4 \\
(>0 \cdot 2)\end{array}$ \\
\hline $\begin{array}{l}\text { BP diastolic } \\
\text { (mmHg) }\end{array}$ & $69 \pm 1 \cdot 8$ & $\begin{array}{l}64 \pm 1.5 \\
(<0.05)\end{array}$ & $\begin{array}{l}63 \pm 1 \cdot 1 \\
(<0.02)\end{array}$ & $\begin{array}{l}64 \pm 1.8 \\
(<0.05)\end{array}$ & $\begin{array}{l}76 \pm 2.9 \\
(<0.02)\end{array}$ & $\begin{array}{l}79 \pm 3.2 \\
(<0.02)\end{array}$ \\
\hline Heart rate per min & $78 \cdot 3 \pm 2 \cdot 90$ & $\begin{array}{l}86.4 \pm 2.88 \\
(<0.01)\end{array}$ & $\begin{array}{l}92.0 \pm 3.28 \\
(<0.01)\end{array}$ & $\begin{array}{l}106.0 \pm 4.09 \\
(<0.001)\end{array}$ & $\begin{array}{l}66 \cdot 7 \pm 2 \cdot 21 \\
(<0.01)\end{array}$ & $\begin{array}{l}64.6 \pm 3.07 \\
(<0.01)\end{array}$ \\
\hline $\begin{array}{r}\text { LVBT } \\
\text { (ms) }\end{array}$ & $303 \pm 5 \cdot 52$ & $\begin{array}{l}254 \pm 7.79 \\
(<0.01)\end{array}$ & $\begin{array}{l}237 \pm 7.33 \\
(<0.001)\end{array}$ & $\begin{array}{l}204 \pm 7 \cdot 49 \\
(<0.001)\end{array}$ & $\begin{array}{l}317 \pm 3.04 \\
(>0.05)\end{array}$ & $\begin{array}{l}313 \pm 6 \cdot 09 \\
(>0 \cdot 1)\end{array}$ \\
\hline $\begin{array}{r}\text { LVFT } \\
\text { (ms) }\end{array}$ & $473 \pm 23 \cdot 89$ & $\begin{array}{l}443 \pm 18.69 \\
(<0.05)\end{array}$ & $\begin{array}{l}429 \pm 19.19 \\
(<0.01)\end{array}$ & $\begin{array}{l}370 \pm 17.04 \\
(<0.01)\end{array}$ & $\begin{array}{l}579 \pm 23.24 \\
(<0.01)\end{array}$ & $\begin{array}{l}588 \pm 36.91 \\
(<0.05)\end{array}$ \\
\hline Ejection fraction & $0.58 \pm 0.02$ & $\begin{array}{l}0.70 \pm 0.03 \\
(<0.01)\end{array}$ & $\begin{array}{l}0.72 \pm 0.04 \\
(<0.001)\end{array}$ & $\begin{array}{l}0.76 \pm 0.03 \\
(<0.001)\end{array}$ & $\begin{array}{l}0.52 \pm 0.03 \\
(>0.2)\end{array}$ & $\begin{array}{l}0.53 \pm 0.03 \\
(>0.2)\end{array}$ \\
\hline $\begin{array}{l}\text { Mean ejection rate } \\
\text { (ED vol/s) }\end{array}$ & $1.92 \pm 0.10$ & $\begin{array}{l}2.78 \pm 0.20 \\
(<0.01)\end{array}$ & $\begin{array}{l}3.02 \pm 0.26 \\
(<0.001)\end{array}$ & $\begin{array}{l}3.78 \pm 0.26 \\
(<0.001)\end{array}$ & $\begin{array}{l}1.65 \pm 0.10 \\
(<0.02)\end{array}$ & $\begin{array}{l}1.67 \pm 0.13 \\
(<0.05)\end{array}$ \\
\hline $\begin{array}{l}\mathrm{dV} / \mathrm{dt} \\
\quad(\mathrm{ED} \mathrm{vol} / \mathrm{s})\end{array}$ & $5.98 \pm 0.26$ & $\begin{array}{l}7 \cdot 07 \pm 0.27 \\
(<0.05)\end{array}$ & $\begin{array}{l}7.65 \pm 0.31 \\
(<0.05)\end{array}$ & $\begin{array}{l}9.74 \pm 0.33 \\
(<0.001)\end{array}$ & $\begin{array}{l}6 \cdot 18 \pm 0 \cdot 31 \\
(>0 \cdot 1)\end{array}$ & $\begin{array}{l}5.59 \pm 0.31 \\
(>0.7)\end{array}$ \\
\hline $\begin{array}{l}\mathbf{d V _ { d } / \mathrm { dt }} \\
\quad(\mathrm{ED} \mathrm{vol} / \mathrm{s})\end{array}$ & $5.65 \pm 0.35$ & $\begin{array}{l}5.73 \pm 0.41 \\
(>0.8)\end{array}$ & $\begin{array}{l}5.64 \pm 0.22 \\
(>0.6)\end{array}$ & $\begin{array}{l}6.43 \pm 0.27 \\
(>0.05)\end{array}$ & $\begin{array}{l}5 \cdot 20 \pm 0 \cdot 22 \\
(>0 \cdot 2)\end{array}$ & $\begin{array}{l}5 \cdot 14 \pm 0 \cdot 40 \\
(>0 \cdot 6)\end{array}$ \\
\hline $\bar{t}_{0}$ (ms) & $156 \pm 3 \cdot 7$ & $\begin{array}{l}116 \pm 3.9 \\
(<0.001)\end{array}$ & $\begin{array}{l}112 \pm 5 \cdot 3 \\
(<0 \cdot 001)\end{array}$ & $\begin{array}{l}94 \pm 3.8 \\
(<0.001)\end{array}$ & $\begin{array}{l}158 \pm 3.0 \\
(>0.3)\end{array}$ & $\begin{array}{l}159 \pm 3 \cdot 0 \\
(>0 \cdot 2)\end{array}$ \\
\hline $\bar{t}_{d}$ (ms) & $201 \pm 13 \cdot 4$ & $\begin{array}{l}181 \pm 7 \cdot 3 \\
(>0.05)\end{array}$ & $\begin{array}{l}165 \pm 7 \cdot 7 \\
(<0 \cdot 01)\end{array}$ & $\begin{array}{l}166 \pm 8 \cdot 2 \\
(<0.02)\end{array}$ & $\begin{array}{l}214 \pm 20.3 \\
(>0.2)\end{array}$ & $\begin{array}{l}221 \pm 23.5 \\
(>0.1)\end{array}$ \\
\hline $\bar{t}_{0} /$ LVET & $0.51 \pm 0.01$ & $\begin{array}{l}0.46 \pm 0.01 \\
(<0.001)\end{array}$ & $\begin{array}{l}0.47 \pm 0.02 \\
(<0.05)\end{array}$ & $\begin{array}{l}0.46 \pm 0.02 \\
(<0.01)\end{array}$ & $\begin{array}{l}0.50 \pm 0.01 \\
(>0.9)\end{array}$ & $\begin{array}{l}0.51 \pm 0.01 \\
(>0.9)\end{array}$ \\
\hline $\bar{t}_{a} /$ LVFT & $0.43 \pm 0.04$ & $\begin{array}{l}0.41 \pm 0.01 \\
(>0.9)\end{array}$ & $\begin{array}{l}0.39 \pm 0.01 \\
(>0.05)\end{array}$ & $\begin{array}{l}0.45 \pm 0.02 \\
(>0.9)\end{array}$ & $\begin{array}{l}0.37 \pm 0.03 \\
(>0.05)\end{array}$ & $\begin{array}{l}0.38 \pm 0.03 \\
(>0.05)\end{array}$ \\
\hline
\end{tabular}

$\star$ Mean \pm one standard error of the mean (SE). Figures in parentheses are the p values for the difference from corresponding resting measurement.

Iso, isoprenaline; Prop., propranolol; LVET, left ventricular ejection time; LVFT, left ventricular filling time; dVS/dt and dVa/dt, peak rate of change of volume in systole and diastole; $\bar{t}_{\text {and }} \bar{t}_{d}$, mean times of ejection and filling; ED vol/s, end-diastolic volumes per second. 
with increasing doses of isoprenaline from $156 \pm$ $10 \mathrm{~ms}$ (SD) at rest to $94 \pm 11 \mathrm{~ms}$ (SD) at the maximum dose of isoprenaline infusion. It returned to resting values after propranolol, with no significant change on reinfusion of $2 \mu \mathrm{g} / \mathrm{min}$ of isoprenaline (Fig. 4). The effect of cycle length alone on $\bar{t}_{\mathrm{s}}$ and $\bar{t}_{\mathrm{d}}$ was examined from data obtained at rest and after each of two successive injections of atropine. The correlation coefficient between $t_{s}$ and LVET was $0.41(p>0.05)$ and between $\mathfrak{t}_{d}$ and the left ventricular filling time (LVFT) this was 0.35 $(p>0 \cdot 1)$ over heart rates ranging from 63 to 121 beats per min $(80.7 \pm 13.9 \mathrm{SD})$. The $\mathrm{t}_{\mathrm{s}} / \mathrm{LVET}$ ratio was 0.54 at rest and did not change significantly after injections of atropine, while the $\bar{t}_{d} / L V F T$ ratio increased progressively with the increase in heart rate (Table 2). After injection of isoprenaline the correlation coefficient between $\bar{t}_{s}$ and LVET was $0.90(p<0.001)$ and between $\bar{t}_{d}$ and LVET this was $0.58(p<0.02)$. A similar but negative correlation was found between $\bar{t}_{s}$ and $E F$ after isoprenaline $(\mathrm{r}=-0.77, \mathrm{p}<0.001)$. The correlation between $\mathfrak{t}_{d}$ and EF was not significant $(r=0.36$, $p>0 \cdot 1)$. The $\bar{t}_{s} / L V E T$ ratio decreased from 0.51 at rest to 0.46 after isoprenaline (Table 1). The $\mathfrak{t}_{\mathrm{d}} / \mathrm{LVET}$ ratio showed variable and insignificant changes. After beta-adrenoreceptor antagonism with or without reinfusion of isoprenaline the values of $\bar{t}_{s}, t_{d}$, and $t_{s} / L V E T$ were not significantly different from the control values. However, $\overline{\mathfrak{t}}_{d} / \mathrm{LVFT}$ ratio was significantly reduced (Table 1. )

\section{Discussion}

Until recently the only available methods for the measurement of dynamic changes in ventricular
Fig. 1 Heart rate and blood pressure changes with increasing doses of isoprenaline and after beta adrenoreceptor antagonism with propranolol.
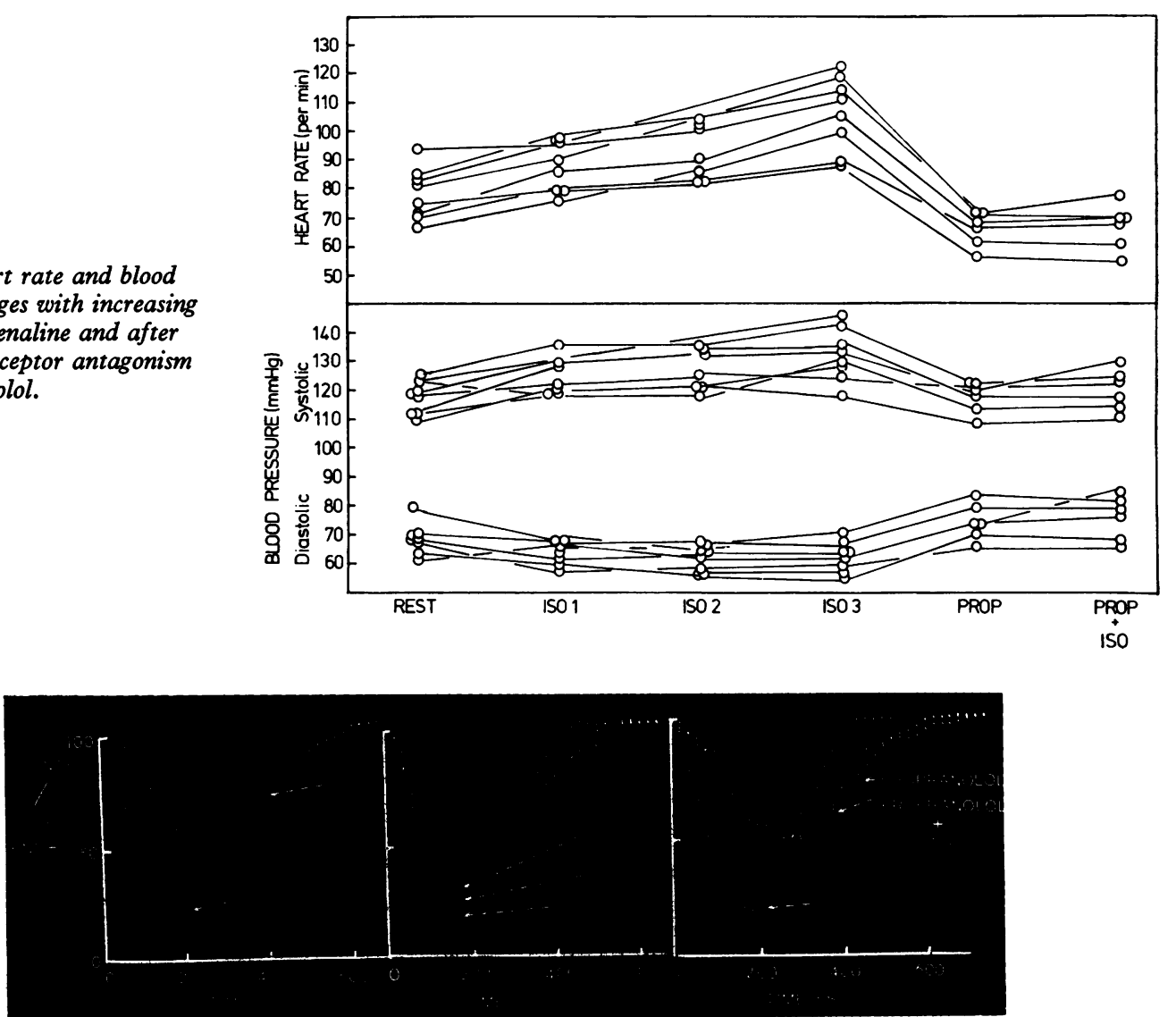

Fig. 2 Ventricular volume curves in one subject at rest and after each of the drugs. Each curve has been accumulated over 500 cardiac cycles and the count rates are expressed as a percentage of the end-diastolic counts. The time on the abscissa is from the peak of the $R$ wave on the electrocardiogram. 
volume in man required either contrast angiography $^{6}{ }^{7}$ or the implantation at surgery of radioopaque markers. ${ }^{8}$ The limitations of single probe TM echocardiography, both on theoretical and practical grounds, are now well recognised. ${ }^{9-11}$

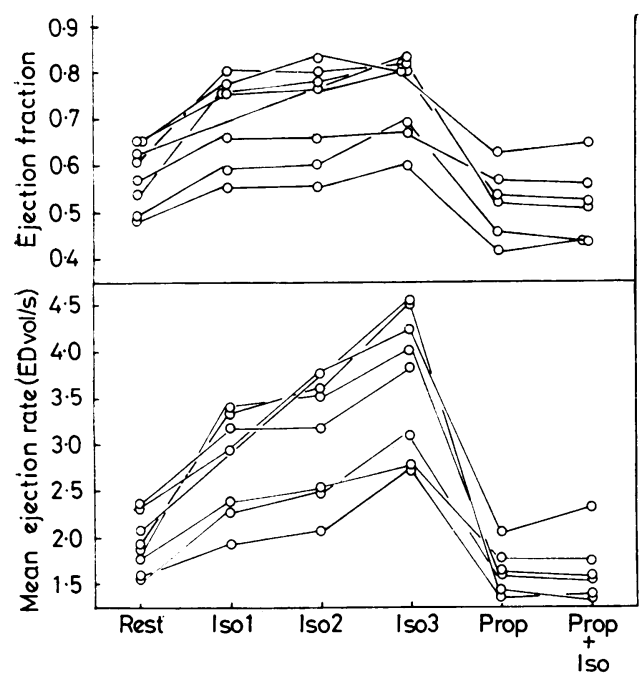

Fig. 3 Changes in ejection fraction and mean ejection rate in individual subjects.

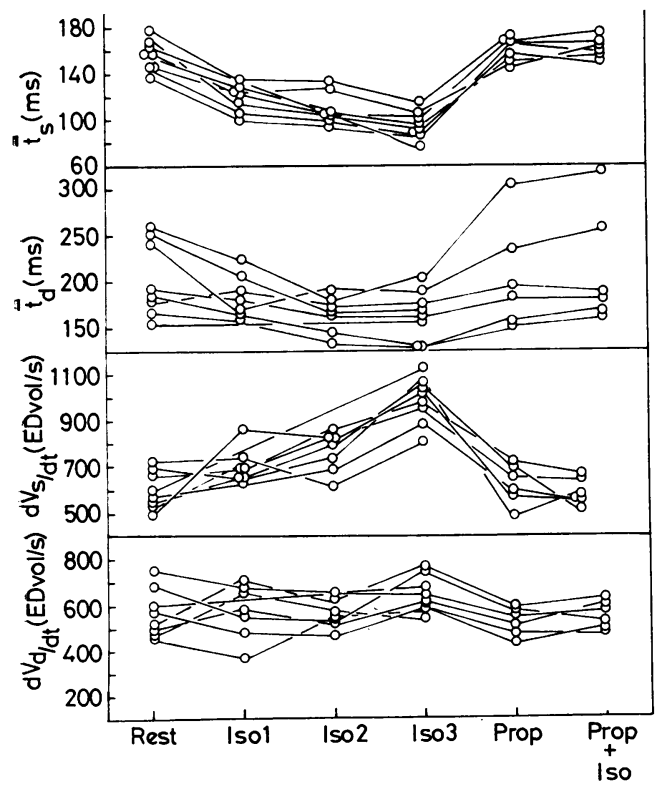

Fig. 4 Changes in the indices of rate of change of volume in systole and diastole with increasing doses of isoprenaline before and after beta adrenoreceptor antagonism with propranolol.
Nuclear angiography provides a useful alternative method, especially when sequential measurements are desired.

Three different approaches have been used for the study of global volume changes by nuclear angiography. Time-activity curves obtained during the first pass of a radioactive bolus ${ }^{512} 13$ have the advantage of a low background, but the disadvantage of relatively poor counting statistics. Furthermore, measurements cannot be repeated more than once during the same study period, except perhaps when using isotopes with ultrashort half-lives. The second approach requires serial accumulations of electrocardiogram-gated images at end-systole and end-diastole; the ejection fraction is then obtained either by computer subtraction ${ }^{14}$ or from geometric area-length analyses. ${ }^{15} 16$ In either case only limited information about the ejection fraction is obtained. The latter method is handicapped by fallacies inherent in assumptions of ventricular geometry and ignores a major advantage of nuclear angiography. No assumptions of geometry need be made in the estimation of volume change by nuclear angiography since count density is proportional to volume.

The third approach is a modification of the second in that numerical data from gated acquisition of count rates are plotted in the form of a composite volume-time curve representing a single averaged cardiac cycle. ${ }^{141718}$ Not only are sequential measurements possible, but information about volume change throughout the cardiac cycle is obtained. This method was therefore chosen for the present study. Since data were accumulated over several cardiac cycles measurements were restricted to "steady state" conditions.

In the present study, drugs with known pharmacolngical actions were chosen to examine the confidence with which changes in myocardial function

Table 2 Effect of atropine on $\vec{t}_{\mathrm{s}}$ and $\bar{t}_{\mathrm{d}}$ and related indices (mean $\pm S E$ )

\begin{tabular}{llll}
\hline & Rest & $\begin{array}{l}\text { Atropine-1 } \\
(0.6 \mathrm{mg})\end{array}$ & $\begin{array}{l}\text { Atropine-2 } \\
(1.2 \mathrm{mg})\end{array}$ \\
\hline No. of subjects & 6 & 6 & 6 \\
RR interval (ms) & $853 \pm 35.57$ & $760.8 \pm 29.19$ & $667 \pm 35.47$ \\
LVET (ms) & $307 \pm 10.19$ & $293 \pm 9.03$ & $280 \pm 8.17$ \\
LVFT (ms) & $546 \pm 30.20$ & $467 \pm 23.96$ & $387 \pm 28.73$ \\
$\overline{\mathrm{t}}_{\mathrm{s}}(\mathrm{ms})$ & $166 \pm 6.34$ & $158 \pm 4.13$ & $153 \pm 8.39$ \\
$\overline{\mathfrak{t}}_{\mathrm{d}}(\mathrm{ms})$ & $231 \pm 22.09$ & $238 \pm 23.79$ & $225 \pm 31.51$ \\
$\overline{\mathrm{t}}_{\mathrm{s}} / \mathrm{LVET}$ & $0.54 \pm 0.03$ & $0.54 \pm 0.02$ & $0.55 \pm 0.02$ \\
$\overline{\mathfrak{t}}_{\mathrm{d}} / \mathrm{LVFT}$ & $0.43 \pm 0.05$ & $0.51 \pm 0.05$ & $0.57 \pm 0.05$ \\
$\begin{array}{l}\text { Ejection fraction } \\
\text { Mean ejection rate }\end{array}$ & $0.45 \pm 0.09$ & $0.46 \pm 0.08$ & $0.47 \pm 0.09$ \\
$\quad(E D$ vol/s) & $1.49 \pm 0.31$ & $\mathbf{1 . 6 1} \pm 0.33$ & $\mathbf{1 . 7 5} \pm 0.40$ \\
\hline
\end{tabular}


can be determined by nuclear angiography. The changes in heart rate and blood pressure were in keeping with the known haemodynamic response to beta-adrenergic stimulation with isoprenaline 1920 and beta-adrenoreceptor antagonism with propranolol. ${ }^{2122}$ The effectiveness of beta-adrenoreceptor antagonism is testified by the absence of significant haemodynamic changes during reinfusion of isoprenaline $(2 \mu \mathrm{g} / \mathrm{min})$.

During infusions of isoprenaline a linear dose dependance is seen for the ejection fraction, mean ejection rate, $d V_{s} / d t$, and $t_{s}$ (Fig. 5). Considering the moderate doses of isoprenaline infusions, the results suggest that changes in myocardial function can be assessed with reasonable confidence by nuclear angiography. A similar order of magnitude of changes in ejection fraction with isoprenaline have been reported previously. ${ }^{23} 24$ Since pacinginduced tachycardia results in a decrease in ejection fraction $(15 \%$ decrease in ejection fraction for a $34 \%$ increase in heart rate) and end-diastolic volume, ${ }^{25}$ the seemingly small increases in ejection fraction during infusions of isoprenaline assume greater significance.

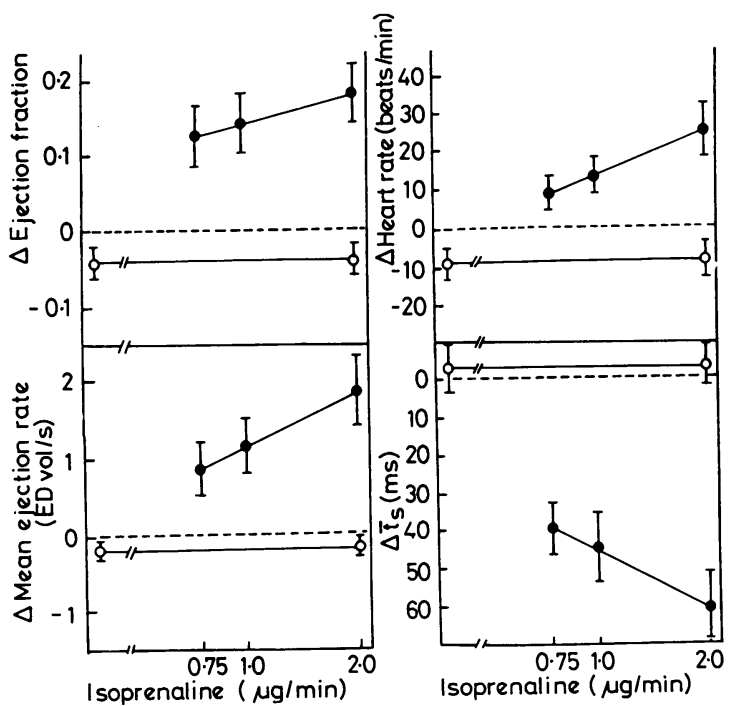

Fig. 5 Dose response curves relating ejection fraction, mean ejection rate, heart rate, and $t_{\mathrm{s}}$ with the dose of isoprenaline plotted on a log scale. Only the mean differences from the resting values (the zero line ------) and $2 S E$ of the differences are shown. Closed circles are the data before beta-adrenoreceptor antagonism and show a linear response to increasing dose levels of isoprenaline. The open circles show the effects of beta-adrenoreceptor antagonism. Infusion of isoprenaline at a dose rate of $2.0 \mu \mathrm{g} / \mathrm{min}$ after propranolol is without effect on these variables.
There are, however, no published data on the other variables measured in this study. Comparison with the classical experiments of Rushmer in intact unanaesthetised dogs shows similar changes in ejection velocity and rate of change of diameter after beta-adrenergic stimulation and block. $^{26}$

The changes in peak rate of change of volume may be expected to be a more sensitive index of changes in myocardial function. This measurement, however, is very sensitive to the degree of filtering to which the data are subjected (unpublished observations). In the present studies care was taken to ensure optimal filtering but, in the absence of a precise mathematical expression that defines the indices of an optimal filter, a certain element of subjective uncertainty is likely to affect adversely the value of this variable when measured at nuclear angiography.

The mean ejection rate, as a measure of the average velocity of flow, is more sensitive than the ejection fraction to changes in the inotropic state. After beta-adrenoreceptor antagonism a small but significant decrease was found in the mean ejection rate but not in the ejection fraction. The mean ejection time $\left(\vec{t}_{s}\right)$ represents the time taken to move 50 per cent of the total volume displaced during systole. The ratio $\bar{t}_{s} / L V E T$ therefore helps to partition the mean ejection velocity into two periods of equal volume displacement. A ratio of 0.5 indicates a symmetrical velocity profile of ejection, whereas values of less than 0.5 indicate a more rapid ejection of the first 50 per cent of the stroke volume compared with the next 50 per cent. The latter would indicate a more forceful and rapid contraction during the earlier parts of systole compared with the later phases of systole, as is expected during inotropic stimulation. In the present study graded infusions of isoprenaline resulted in a progressive shortening of $\vec{t}_{\mathrm{s}}$ and a decrease in $\bar{t}_{s} / L V E T$ ratio in association with a larger stroke volume and ejection fraction. On the other hand, tachycardia induced with atropine is without effect on the $\bar{t}_{s} / L V E T$ ratio and hence the velocity profile of ejection. A significant advantage is that unlike the $d_{\mathrm{s}} / \mathrm{dt}$ values, $\bar{t}_{\mathrm{s}}$ is not affected much by the filter bandwidth (unpublished observations).

In conclusion, therefore, volume-time curves obtained at nuclear angiography provide reasonably accurate and sensitive quantitative information about the function of the cardiac pump. As a noninvasive technique, the method is particularly suited for the study of physiological and pharmacological interventions and also longitudinal follow-up studies. 


\section{References}

${ }^{1}$ Muir AL, Hannan WJ, Brash HM, Baldwa V, Miller HC, Ogilvie B. The assessment of left ventricular ejection fraction in patients with ischaemic heart disease by contrast ventriculography and nuclear angiography. Clin Sci Mol Med 1977; 53: 55-61.

${ }^{2}$ Green MV, Brody WR, Douglas MA, Redwood DR, Bailey JJ, Johnston GS. Count rate measurements of left ventricular ejection fraction from gated scintigraphic images (abstract). $\mathcal{f}$ Nucl Med 1976; 17: 557. ${ }^{3}$ Burow RD, Strauss HW, Singleton R, et al. Analysis of left ventricular function from multiple gated acquisition cardiac blood pool imaging. Comparison to contrast angiography. Circulation 1977; 56: 1024-8. ${ }^{4}$ Folland ED, Hamilton GW, Larson SM, Kennedy JW, Williams DL, Ritchie JL. Radionuclide ejection fraction: a comparison of three radionuclide techniques with contrast angiography. $\mathcal{F}$ Nucl Med 1977; 18: 1159-66.

${ }^{5}$ Hannan WJ, Hare RJ, Hughes SHC, Scorgie RE, Muir AL. Simplified method of determining left ventricular ejection fraction from a radionuclide bolus. Eur $\mathcal{F}$ Nucl Med 1977; 2: 71-4.

${ }^{6}$ Dodge HT, Sandler H, Ballew DW, Lord JD Jr. Use of biplane angiocardiography for the measurement of left ventricular volume in man. Am Heart $\mathcal{F} 1960$; 60: 762-76.

'Sandler H, Dodge HT. The use of single plane angiocardiograms for the calculation of left ventricular volume in man. Am Heart $\mathcal{F}$ 1968; 75: 325-34.

${ }^{8}$ Harrison DC, Goldblatt A, Braunwald E. Studies on cardiac dimensions in intact, unanaesthetized man. 1. Description of techniques and their validation. Circ Res 1963; 13: 448-55.

${ }^{9}$ Feigenbaum H. Echocardiographic examination of the left ventricle (editorial). Circulation 1975; 51: 1-7.

${ }^{10}$ Teichholz LE, Kruelen T, Herman MV, Gorlin R. Problems in echocardiographic volume determinations: echocardiographic-angiographic correlations in the presence or absence of asynergy. Am $\mathcal{f}$ Cardiol 1976; 37: 7-11.

11Fortuin NJ, Pawsey CGK. The evaluation of left ventricular function by echocardiography. $\mathrm{Am} \mathcal{F} \mathrm{Med}$ 1977; 63 : 1-9.

${ }^{12}$ Schelbert HR, Verba JW, Johnson AD, et al. Nontraumatic determinations of left ventricular ejection fraction by radionuclide angiocardiography. Circulation 1975; 51 : 902-9.

${ }^{13}$ Myers RW. Single transit non-gated radionuclide angiocardiography for assessing left ventricular wall motion and ejection fraction. Clin Nucl Med 1976; 1: 191-7.
${ }^{14}$ Secker-Walker RH, Resnick L, Kunz H, Parker JA, Hill RL, Potchen EJ. Measurement of left ventricular ejection fraction. $\mathcal{F}$ Nucl Med 1973; 14: 798-802.

${ }^{15}$ Sullivan RW, Bergeron DA, Vetter WR, Hyatt $\mathrm{KH}$, Haughton V, Vogel JM. Peripheral venous scintillation angiocardiography in determination of left ventricular volume in man. Am $\mathcal{F}$ Cardiol 1971; 28: 563-7.

${ }^{16}$ Strauss HW, Zaret BL, Hurley PJ, Natarajan TK, Pitt B. A scintiphotographic method for measuring left ventricular ejection fraction in man without cardiac catheterisation. Am $\mathcal{F}$ Cardiol 1971 ; 28 : 575-80.

${ }^{17}$ Bacharach SL, Green MV, Borer JS, Douglas MA, Ostrow HG, Johnston GS. A real-time system for multi-image gated cardiac studies. $f$ Nucl Med 1977; 18: $79-84$.

${ }^{18}$ Bacharach SL, Green MV, Borer JS, Ostrow HG, Redwood DR, Johnston GS. ECG-gated scintillation probe measurement of left ventricular function. $\mathcal{F}$ Nucl Med 1977; 18: 1176-83.

${ }^{19}$ Dodge HT, Lord JD, Sandler H. Cardiovascular effects of isoproterenol in normal subjects and subjects with congestive heart failure. Am Heart $\mathcal{F}$ 1960; 60: 94-105.

${ }^{20}$ Krasnow N, Rolett EL, Yurchak PM, Hood WB Jr, Gorlin R. Isoproterenol and cardiovascular performance. Am $\mathcal{F}$ Med 1964; 37: 514-25.

${ }^{21}$ Epstein SE, Robinson BF, Kahler RL, Braunwald E. Effects of beta-adrenergic blockade on the cardiac responses to maximal and sub-maximal exercise in man. f Clin Invest 1965; 44: 1745-53.

${ }^{22}$ Macdonald HR, Sapru RP, Taylor SH, Donald KW. Effect of intravenous propranolol on the systemic circulatory response to sustained handgrip. $A m \mathfrak{F}$ Cardiol 1966; 18: 333-43.

${ }^{23}$ Harrison DC, Glick G, Goldblatt A, Braunwald E. Studies on cardiac dimensions in intact, unanesthetized man. IV. Effects of isoproterenol and methoxamine. Circulation 1964; 29: 186-94.

${ }^{24}$ Hinds JE, Hawthorne EW. Comparative cardiac dynamic effects of dobutamine and isoproterenol in conscious instrumented dogs. Am F Cardiol 1975; 36: 894-901.

${ }^{25}$ Ricci DR, Ingels NB Jr, Daughters GT II, Stinson EB, Alderman EL. Intrinsic relationship of heart rate and ejection fraction in man (abstract). Circulation 1976; 53 \& 54, suppl II: 31.

${ }^{26}$ Van Citters RL, Baker D, Rushmer RF. Cardiac adrenergic blockade with DCI in the intact unanesthetized animal. Am $\mathcal{F}$ Physiol 1961; 200: 990-4.

Requests for reprints to Professor R P Sapru, Sree Chitra Tirunal Medical Centre, Trivandrum 695011, India. 